\title{
OBSERVATIONS ON THE COURSE OF THE OPTIC FIBRES IN A CASE OF UNILATERAL OPTIC ATROPHY.
}

BY W. B. WARRINGTON, M.D., M.R.C.P.

Demonstrator of Pathology in University College, Liverpool; Assistant Physician to the Hospital for Chest Diseases, and Pathologist to the Stanley Hospital.

AND

J. E. DUTTON, M.B.

Late Holt Fellow in Pathology.

(From the Thompson-Yates Laboratory.)

That in man a semi-decussation of the optic nerves occurs at the chiasma is almost universally believed; the fact, however, that the veteran histologist Kölliker disputes this position has given a fresh impetus to observations on the question.

Kölliker's position, as described in the last edition of the Handbuch der Gewebelehre, is that pure anatomy yields evidence of a complete crossing in man, in the dog and the cat.

His observations were made by serial horizontal sections through the chiasma stained by the Weigert method.

In order to study the course of the fibres a complete series must be made; this is not easy and Kölliker criticises Gudden's original pictures on the ground that they are merely schematic, and that the distinct uncrossed bundle there figured can never be found in nature.

Kölliker (1) has again only last year returned to the subject, and has studied, by means of the Golgi method, the course of fibres in the chiasma of sheep, cats and man. The results he has obtained are that in man it is impossible that any considerable number of fibres pass to the tract of the sime side as the optic nerve from which they are derived, 
though he admits the existence of a very small number of direct fibres.

In addition to this conclusion Kölliker has noticed the important fact that in the cow, cat, rabbit and dog, a division of individual fibres takes place in such a manner that a fibre from one optic nerve passes to the two tracts.

In man Kölliker was only able to find in his specimens one such fibre.

Should further observations demonstrate that division of fibres is a constant occurrence in the chiasma, Kölliker considers this fact would remove in considerable part the physiological objections to his view.

Finally Kölliker urges that the minute anatomy of the chiasma inust be more thoroughly observed before the question is settled.

Other authors also favour the view that the decussation is complete, viz., Biesiadecki (2) in 1861, Mandelstamm (3) 1873, Scheel, W. Krause, 1897, and especially Michel (4) 1873-1890.

Mickel maintains :-

(1) That serial sections of the chiasma give no support to the view of semi-decussation.

(2) That investigations of degenerations in man and animals give no evidence of a non-crossed bundle of fibres.

(3) "He argues that if homonymous bilateral hemianopsia is to be explained by the decussation in the chiasma, the proportion of crossed to uncrossed fibres should be as $1 \cdot 1$, and contrasts with this the admission of even those who adhere to the doctrine of partial decussation, that the relation is $3 \cdot 1$, or $4 \cdot 1$, at most as $5 \cdot 3$." (Quoted from Barker, "The Nervous System.")

Our case does not, however, show any marked difference between the amount of degeneration in the two tracts. Further, owing to the limitation of the field of vision, the outer and lower parts of the retina are probably less developed than the inner and lower, and, as Michel himself has found, the number of fibres passing to different sections of the retina is very variable, being least in the outer segment. 
Michel also cites the fact that no anatomical evidence has yet been produced demonstrating the double representation of the macula, which is required by the theory of semi-decussation in order to explain the freedom of the fixation point in cases of hemiopia. Michel's hypothesis cannot, however, be regarded as giving a more satisfactory explanation.

Finally Kölliker has been attacked on his own ground by Grützner (5) who, in an admirable critical article, concludes that anatomy can give no definite reply to the question of the complete or partial decussation of the optic fibres. This author made models of the chiasma, in which one half of the fibres were made to cross, the other half to remain on the same side. The models were then embedded in paraffin and cut into a series of horizontal sections. From a study of these sections he states that if he had wot been in possession of the actual facts, he would have judged that all the fibres were crossed.

In view of the renewed interest which the subject has thus recently attracted we thought it permissible to bring forward the following case of unilateral atrophy of an optic nerve, which shows clearly the existence and arrangement of a semi-decussation in the chiasma, and furnishes also some other points of interest.

\section{Rísumé of Case.}

Sarah B., aged 63, admitted to the Liverpool Royal Infirmary on January 14, 1898, under the care of Dr. Caton, to whom we are indebted for permission to record the case. Three years previously the patient had received an injury to the right eye, and six months before admission enucleation became necessary and was performed at the Stanley Hospital. On admission to the Royal Infirmary the patient was found to have a greatly enlarged liver. Death occurred in about three weeks after admission, and the autopsy revealed the presence of a large melanotic growth in the liver.

We record here :-

(1) The resulting degenerations in the nerve, chiasma and optic tracts. 
(2) The existence of undegenernted fibres in the atrophied nerve.

(3) The condition of the oculonotorius nuclens.

\section{Method of HXamination.}

The whole brain was hardened in Müller's fluid, the optic system, with the neighbouring parts of the brain undisturbed, was then removed. By this means it was easy to localise the position of any degenerations that might be found.

The optic chiasma with pieces of each tract and both nerves was removed and placed in Marchi's fluid. The remaining extent of the tracts, with the adjoining brain tissue, including the geniculate bodies and pulvinar, was cut into small sections, $3 \mathrm{~mm}$. in thickness, transverse to the long axis of the tract fibres. These, together with separate pieces of both optic nerves, were also placed in Marchi fluid. The tissues were afterwards embedded in paraffin, cut in serial sections of $10 \mu$ each and then fixed on slides. The chiasma was cut into a complete series of horizontal sections, the remaining parts were cut transversely. As no fibres showed the characteristic Marchi globules they were stained with the acid hæmatoxylin of Schäfer and then treated with Pal's fluids.

This method of paraftin embedding has the advantages that a complete series may be cut, and that the sections are much thinner than can be obtained by the celloidin method. The previous treatment of the tissues by the Marchi fluid enables the hæmotoxylin to stain perfectly well.

\section{I.-The Resulting Degenerations of the Nerve, Chicesma, and 'racts.}

The naked eye examination of the sections showed that the right optic nerve was completely degenerated, being white and shrunken.

The optic tracts were plainly seen to contain sclerosed tissue, which stood out markedly in contrast to the blachstained nerve-fibres. 
Optic nerves.-T'he left nerve showed the normal structure. The right practically consisted of fibrous tissue; it was very much shrunken and complete atrophy appeared to have taken place.

Careful examination, however, with a $\frac{1}{12}$ in. immersion lens, discovered a few normal nerve-fibres, scattered irregularly over the area of the section. In diameter they never measured more than $1.5 \mu$, and hence belonged to the smallest of the optic nerve-fibres (see plate, fig. 1).

Chiasma.-The chiasma, with the optic nerves attached as described, was cut in a complete series of about 500 horizontal sections, and every fourth one stained. By means of this large number of fairly thin sections, the course of the degenerated tracts could be fairly well traced, and is shown in the accompanying diagrams (figs. 1-5). In the sections about the median plane (figs. 3 and 4 and plate, fig. 4) the atrophy from the right nerve is seen spreading in the central portion of the same-sided tract, and occupying the front and back of the chiasma-its extent being larger in the latter situation.

As the sections approached the upper and lower surfaces the distribution of atrophied tissue was less defined, and the intermingling of normal fibres was greater. The general relations were, however, the same. In looking at figs. 3 and 4 it seems difficult to resist the conclusion that the atrophied tract at $B$ corresponds with the normal fibres at A. The general "grain" of the fibres of the left nerve appear to be sweeping into the left tract, much as the atrophic tissue of the right nerve passes out of the right tract.

Is it possible, despite the observations of Grützner, to rely upon the anatomical evidence?

When we examined this region $(A)$ in very thin sections $(6 \mu)$ with ocular 4 Zeiss, and ${ }_{1}^{\frac{1}{2} \text { th }}$ inch objective, large strands of fibres cut in longitudinal direction were certainly seen passing in two directions, viz.: (1) streaming through the chiasma; (2) curling round to enter the tract of the same side.

The sections were so thin that the curve on groups of 


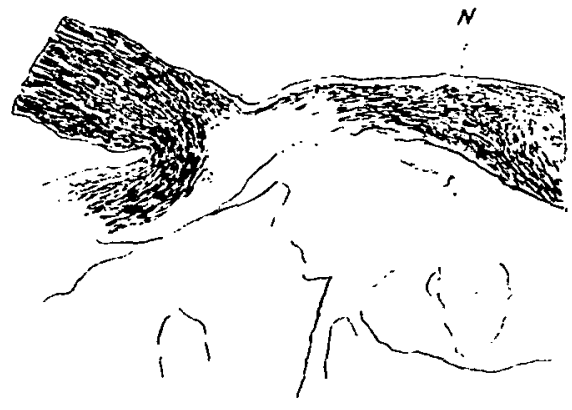

Fig. 1.

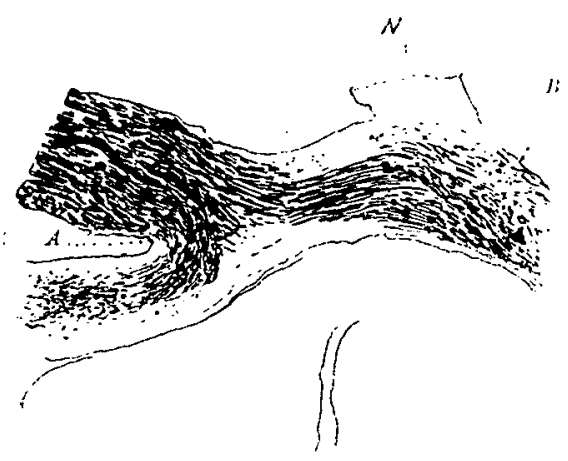

FrG. 3.

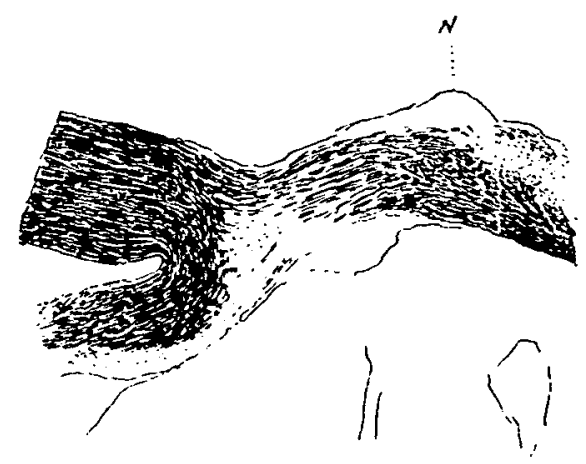

FIG. 2.

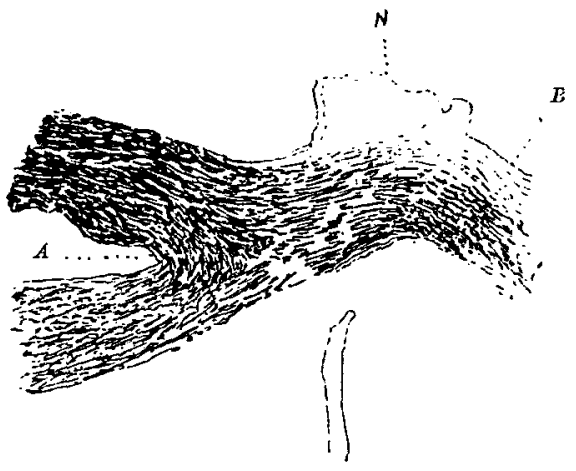

Fig. 4.

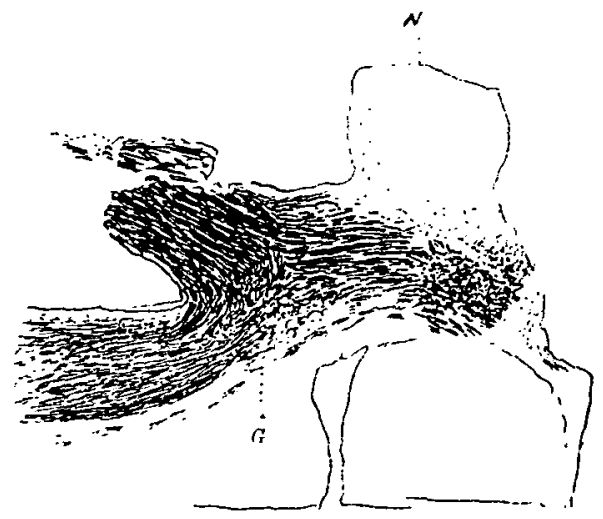

Fig. 5.

Figs. 1 to 5.

Series of drawings of horizontal sections of chiasma, made by Edinger's apparatus. Fig. 1 is the most dorsal, fig. 5 the most ventral section.

$N=$ Atrophied right optic nerve.

$A=$ Junction of left nerve with left tract.
$G=$ Gudden's commissure.

$B=$ Junction of right nerve with right tract. 
individual fibres could be distinctly seen, and we wre inclined to think that the appearance represented an anatomical fact. As pointed out by Michel, the fibres of the optic nerve, as they enter the chiasma, turn sharply at right angles, and again at another right angle when entering the tract of the opposite side. It is this fact which is the cause of the deceptive appearance in anatomical preparation, inclining the observer to believe the fibres enter the tract from the nerve of the same side.

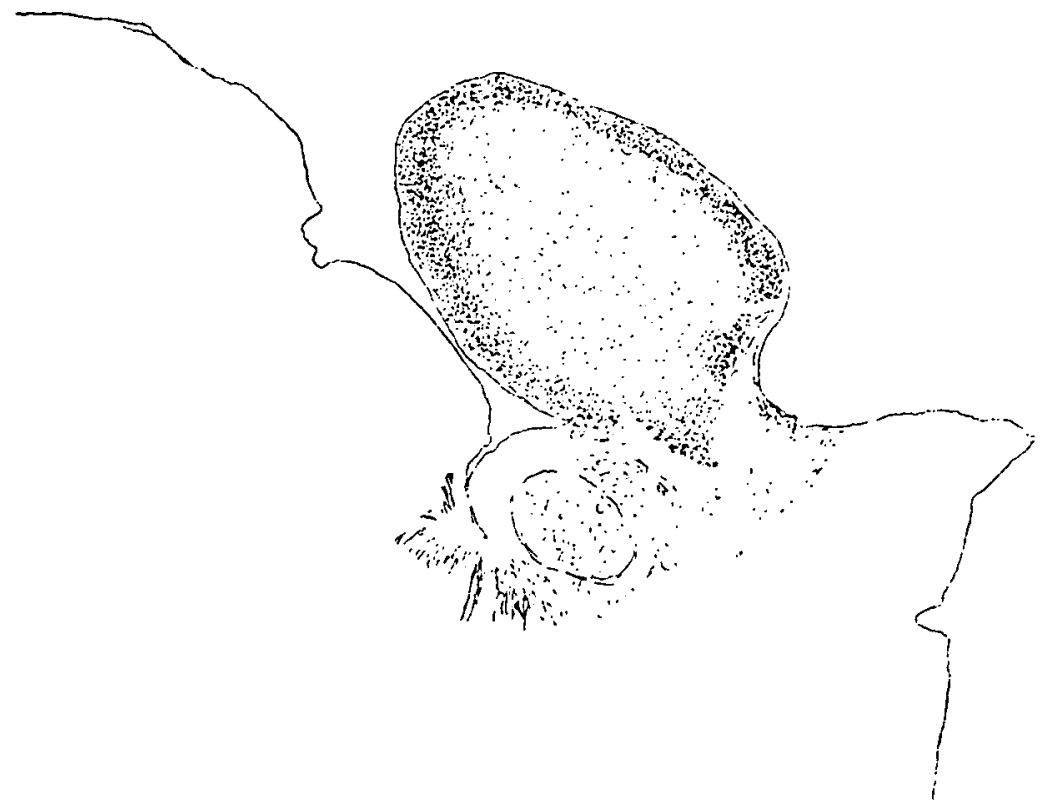

Fig. 6.

Bearing in mind this warning, we are yet of opinion that is not sufficient to explain the appearances alluded to. In these very thin sections groups of fibres having the same direction can be traced along the outer border of the nerve and into the tract of the same side.

Right optic tract.-Sections taken near the chiasma shorved that the atrophy occupied a central position extending further outwards than inwards (figs. 6, 7,8 ). 
Microscopical examination revealed that in no part was there complete atrophy, normal nerve fibres being found in the most affected part of the tract. Many of the uomal fibres found in the atrophic tissue were of small diameter $(1.5-2 \mu)$, only the minority being as large in diameter as $5-7.5 \mu$; whereas at the periphery of the section these large fibres greatly preponderated (plate, figs. 2 and 3 ).

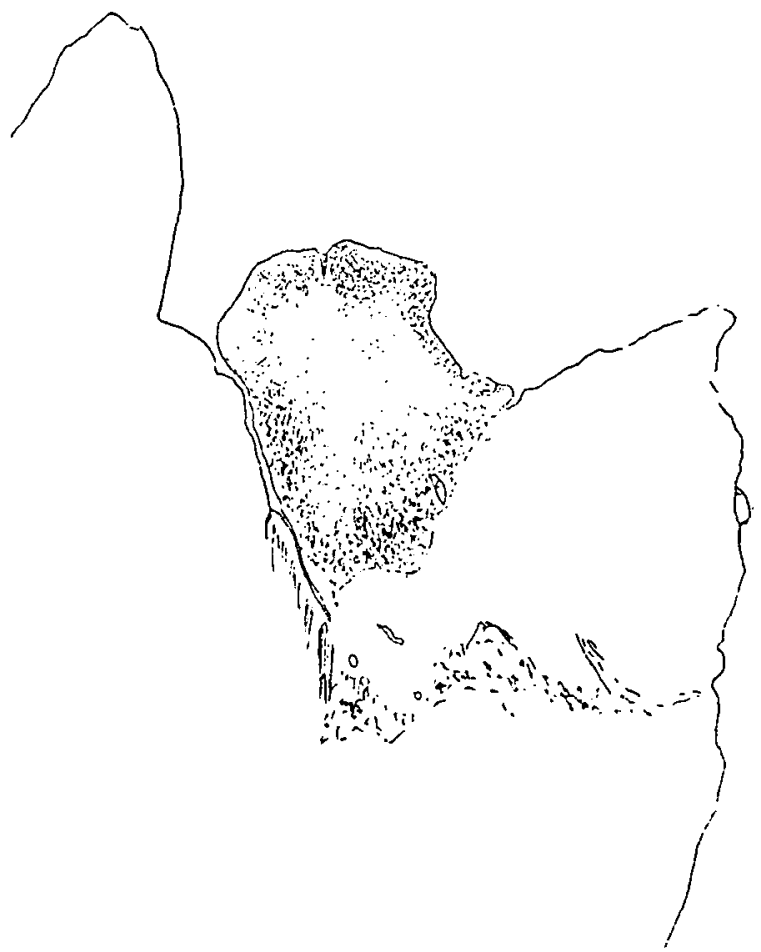

Fig. 7.

The same general distribution was noted in the sections taken from the more centrally situated part of the tract, but the extent of the atrophy gradually diminished.

At the commencement of the level of the exterval geniculate body no obvious degeneration was seen, but microscopically the fibres on the outer part of the tract 


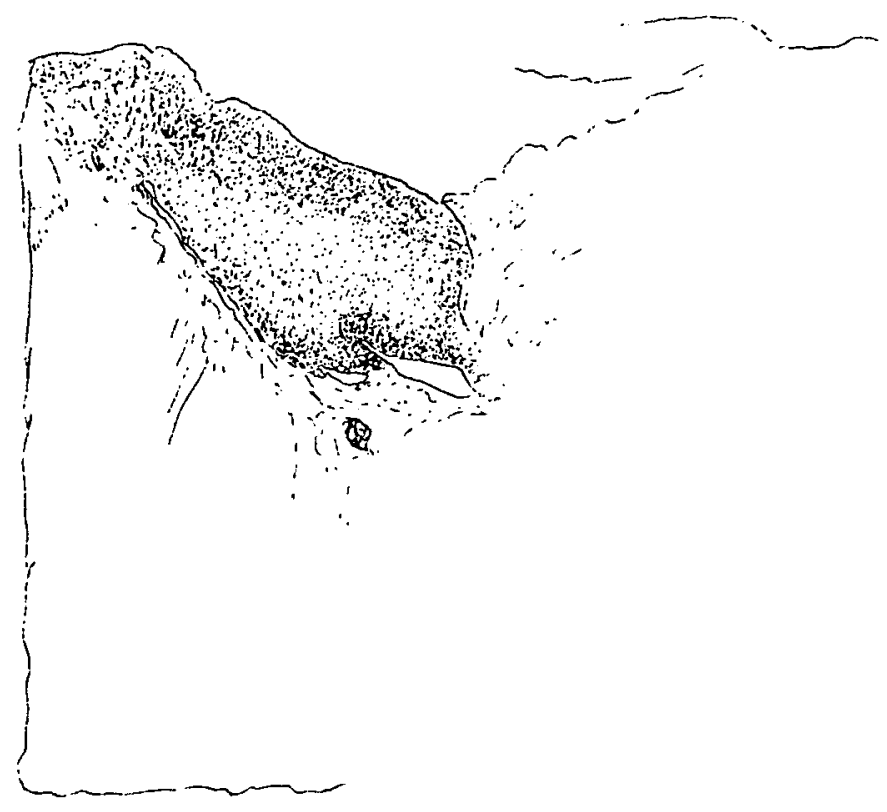

Fig. 8.

Figs. 6 ro 8.

Series of drawings of transverse sections through the right optic tract. Fig. 6 is nearest the chiasma, fig. 8 near the geniculate body.

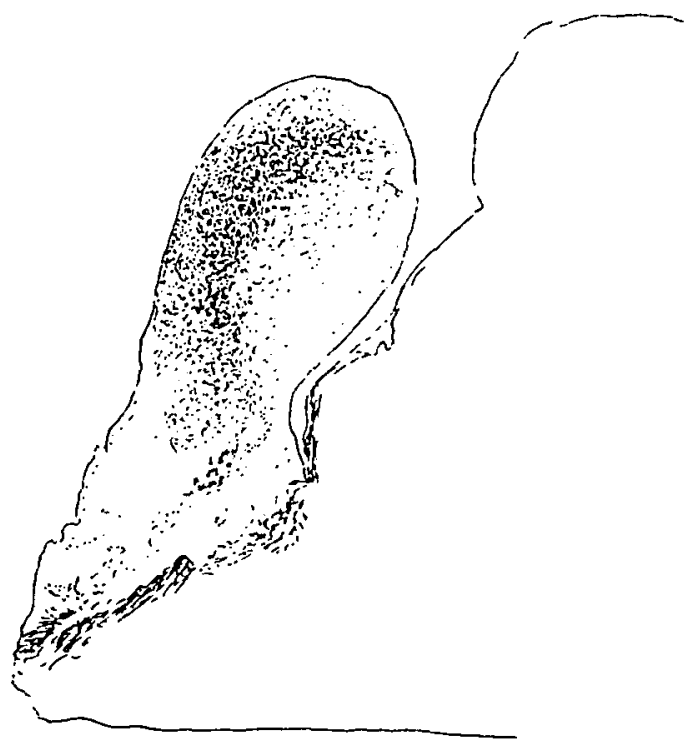

Fig. 9. 


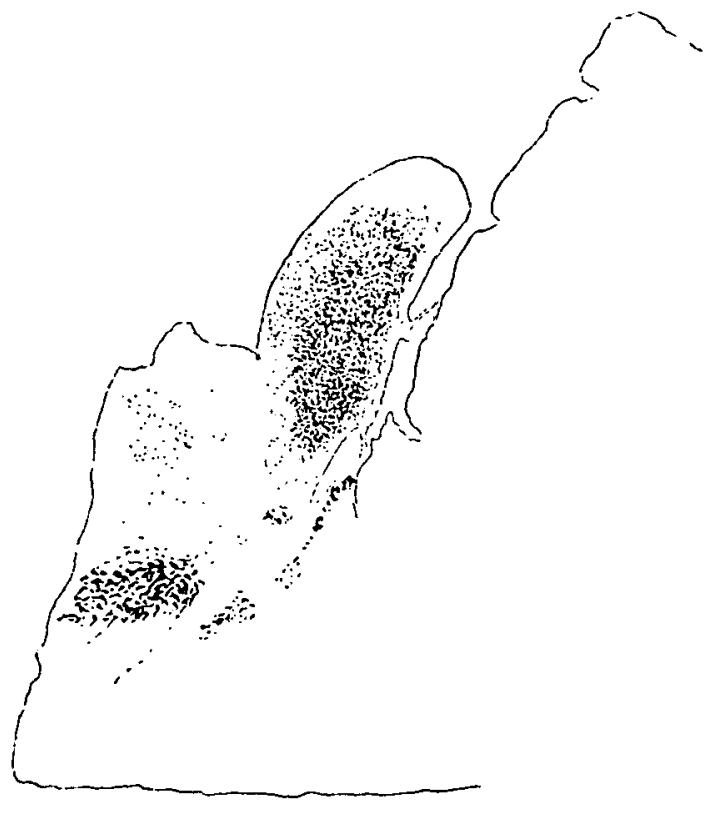

Frg. 10.

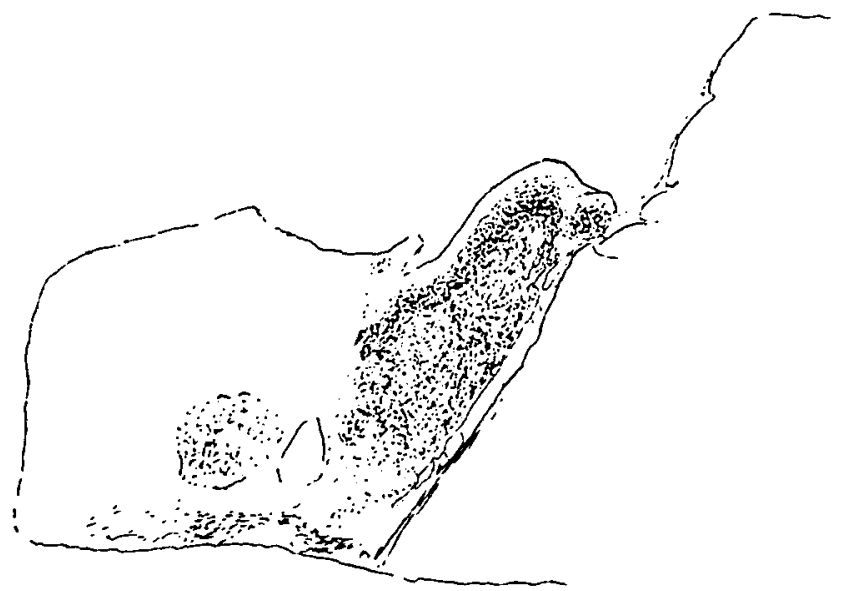

Fig. 11.

Figs. 9 то 11.

Series of drawings of transverse sections through the left optic tract. Fig. 9 is nearest the chiasma, fig. 11 near the geniculate body. 
were considerably larger and more numerous than those on its inner aspect. Sections through the geniculate body showed that its cellular mass was richly covered by fibres of a large diameter; those deeper in its substance were much smaller.

Left optic tract.-In sections near the chiasina the degeneration is well seen, situated peripherally and chiefly on the inner and inferior aspect of the tract. It is never complete, normal nerve-fibres being present in the connective tissue. Its extent gradually diminishes, as it is traced centrally (figs. 9, 10, 11).

Near the geniculate body the area of degeneration could no longer be observed with the naked eye, but on microscopic examination, the inferior region was found scantily supplied with nerve-fibres.

No obvious difference in size was found between those normal fibres situated in the atrophied region and those composing the undegenerated portion of the optic tract.

\section{Rematrks.}

'Those who, on anatomical grounds, oppose the prevalent view of a semi-decussation of the optic nerve-fibres, must explain the degeneration appearances in cases similar to ours.

Michel (6) appears to be the only observer: who, using the modern methods, has given cases of degeneration and maintained that these support the view of a complete decussation. He mentions and illustrates four such cases which, however, do not appear to us to justify his position; for if, as his figures show, there is no degeneration visible in the tract on the same side as the atrophy-there is only partial atrophy in the opposite tract-indeed, as Wieting has remarked, the unprejudiced observer would draw the opposite conclusion to that which Michel does from a study of his figures. The very old observations of Biesiadecli, the more recent ones of Mandelstamm, were made on unstained preparations, and cannot well be compared with Weigert-Pal specimens. 
On the other hand, Purtscher (7) records six cases, Wieting (8) three, Siemerling (9) and Williamson (10) one case, stained by the Weigert method, which clearly show the atrophy in both tracts, and in a similar position to that described by us, viz., the crossed fibres occupy the centre of the tract, the uncrossed the periphery. Marchand (11) and Burdach (12) give figures showing clearly atrophy in both tracts, but having a different position.

Hellendall (13) quotes three well illustrated cases showing that the crossed bundle occupied an inner and ventral position in the tract, whilst a triangular field of atrophied tissue was situated just at the commencement of the samesided tract, which could not, however, be traced any further.

Hellendall and also Hausemann (14), who criticised the cases, considered that the preparation showed also anatomical evidence of the existence of uncrossed fibres in the tract on the same side as the normal nerve.

Thus summarising we may state :-

(1) That all observers with the modern methods, with the single exception of Michel, are of opinion that degenerations occur in both tracts after destruction of one optic nerve.

(2) That whilst in general pure anutomy cannot demonstrate a decussation, certain cases, e.g., Hellendall's and the present writers', yield some evidence of an uncrossed bundle of fibres.

(3) That the commonest position in which such degenerations in the tracts have been found corresponds to that described above.

\section{II.-On the Existence of Undegenerated Fibres in the Atrophied Norve.}

We alluded to the presence of very fine normally-stained tibres in the stump of the atrophied nerve, and to the fact that the fibres remaining in the degenerated portion of the tract of the same side also had an extremely small diameter.

Gudden long ago asserted that the fine fibres of the optic nerve were connected with the anterior corpus quadrigeminum, whilst those of larger diameter could be traced 
to the geniculate body. Michel very clearly figures similar fibres, Williamson and Wieting also found them, and the latter observer suggested they might be centrifugal in their. course.

Hitherto the existence of centrifugal fibres in the optic nerve has been demonstrated by the Golgi method, and their origin could not be ascertained in this way. Recently, however, Wallenberg (15), Boyce and Warrington (16) showed that in the bird a lesion of the optic lobes gave rise to a degeneration extending to the opposite retina. These various observations certainly suggest that the fine fibres may belong to centrifugal neurons, though the evidence adduced is not sufficient to show where their cell origin is.

As shown in the photograph (plate, figs. 2 and 3 ) the small size of the fibres in the degenelated centre of the tract in comparison with those of the normal periphery is very noticeable, and suggests the possibility that they may belong to the same system as those found undegenerated in the atrophied stump, viz., have a centrifugal course.

\section{III.-On the Condition of tiue Oculomotorius Nucleus.}

A series of paraftin sections was made, including the whole of this nucleus, and every fifth section stained by Held's modification of the Nissl method. It is now well known that section of an axis cylinder is followed in general after a short time by the change known as chromatolysis in its nerve cell. Further, that after a considerable period the cells so affected tend gradually to return to their normal condition. In our case the cells of the nucleus were throughout normai. It is possible that this repair may have taken place, as olservation by Van Gehuchten, Marinesco, and one of us have shown that after a period of 100 days not any very obvious difference is noticeable in any group of cells whose axons have been cut. The application of the law of Nissl for the limitation of a nucleus of origin is not always. very satisfactory. Bernheimer (17) and Schwabe (18) have made laborious researches on the connections of the various parts of the oculomotorius nucleus, but their results are 
not in close agreement. Thus Bernheimer considers that the external muscles of the eye receive in the main a crossed innervation from the nucleus, whilst Schwabe regards the nerve to the superior rectus as alone derived from the opposite side of the nucleus. This author also was unable by this method to locate the nucleus of the internal eye muscles, whilst Bernheimer refers to the cells situated on the lateral part of the nucleus as giving origin to the nervefibres which supply these muscles.

In experiments performed by one of us (19), in which the third cranial nerve was divided within the cranium and the oculomotorius nucleus subsequently examined, only changes of a slight nature were found, which were useless for purposes of careful localisation. It is probable that in the case of the eye muscle our efforts should be directed to the localised of cell groups representing combinations rather than single movements.

\section{REFERENCES.}

(1) KöLLIKER. Festschrift der Phys, Med. Gesellschaft, Wiirzburg, 1899.

(2) BiesIadeckI. Sitzurgsb. d. k. Akad.d. Wissenschaft., Math., naturwiss., Wiln, Bd. xlii. (1861), S. 86.

(3) Mandelstamm. Arch. f. Ophth., Berl., Bd. xix. (1873); 2 Abth., S. 39-58.

(4) Michel. Festschrift der Med. Fak. d' Univ. Wiirzburg, Wiesbaden, 1887 ; Arch. f. Ophth., Bd. xxx., 2 Abth., 1893.

(5) Grütznen. Deutsche. Med. Wochen., Bd. xxiii., 1897, S. 2.

(6) MICHEL. Loc. cit.

(7) Pogtschen. Arch. f. Ophth., Bd. zxvi., 1886.

(8) Wieting. Arch.f. Ophth., Bd. xlv., 1898.

(9) Simmenling. Arch. f. Psychiatrie and Nervenk., Bd. xix., 1888.

(10) Williamson. Brain, 1882.

(11) Marchand. Arch.f. Opthth., Bd. xxviii., 1882.

(12) Burdach. Arch.f. Ophth., Bd. xxix., 3rd Abth., 1883.

(13) Hellendace. Arch.f. Anat. d Phys., 1897, S. 497.

(14) Hausemans. Ibid.

(15) Walcenberg. Neurolog. Centralb., 1898.

(16) Boyce and Warrington. Phil. Trans. R. S., B., vol. 191.

(17) Bernheimer. Wien. Klin. Wochen., 1896.

(18) Schwabe. Neur. Centralb., 1896.

(19) Warbingtox. Joum. of Phys., xxiii., 1898.

The above references are fairly complete as regards cases which bave occurred in the buman subject. The literature dealing with the general subject is extremely large and is to be found in the works of Gudden, Michel and $\nabla$. Monakow. 


\section{DESCRIPTION OF PLATES.}

Photographs takeu from sections stained by Schäfer's acid hæmatoxylin method. The black masses represent osmic stain which was not removed by washing. Black rings are normal nerre-fibres.

FJg. 1.

Right optic nerve showing a few undegenerated nerve-fibres in the sclerosed tissue. (Zeiss $8 \mathrm{~mm}$. Apochromatic Oc. 3.)

Erig. 2.

Periphery of right optic tract consistiug chiefly of largish fibres. $\frac{1}{3}$ in. .obj., Oc. 3 .

Fig. 3.

Centre of right optic tract consisting chiefly of small fibres. $\frac{3}{3}$ in. obj., .)c. 3.

Fig. 4.

Section through the centre of chiasma ( $6 \mu$ in thickness). 
PLATE.

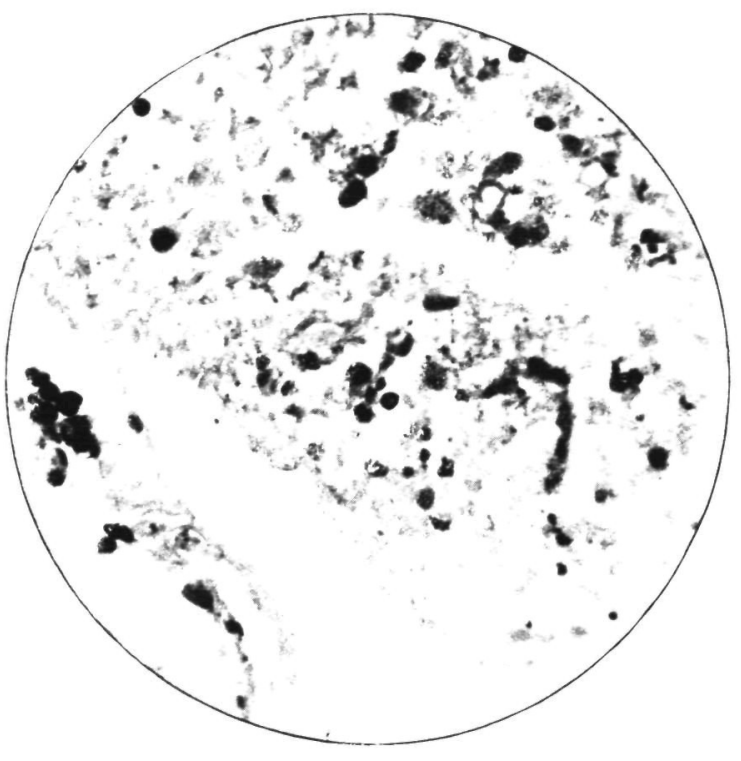

FIG. 1.

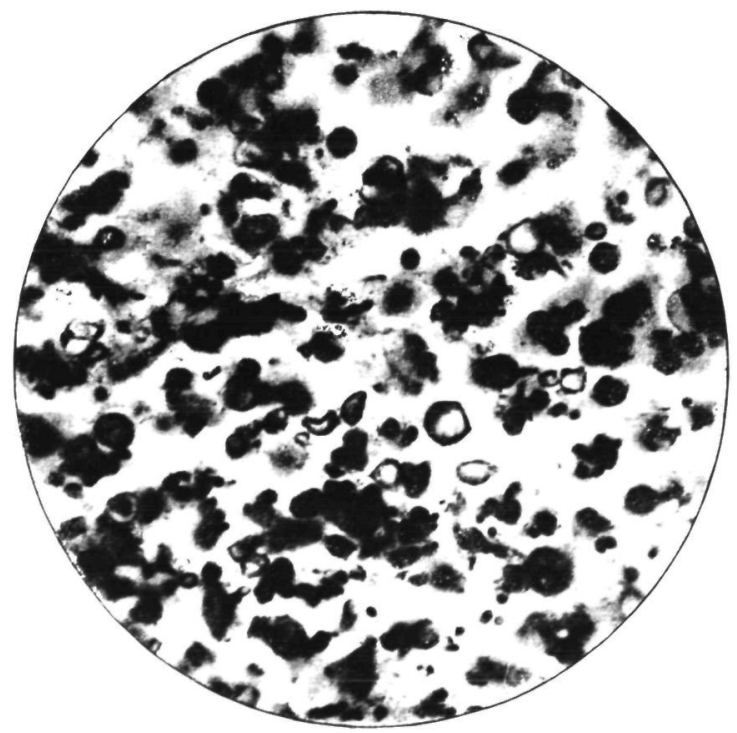

FIG. 2. 


\section{PLATE.}

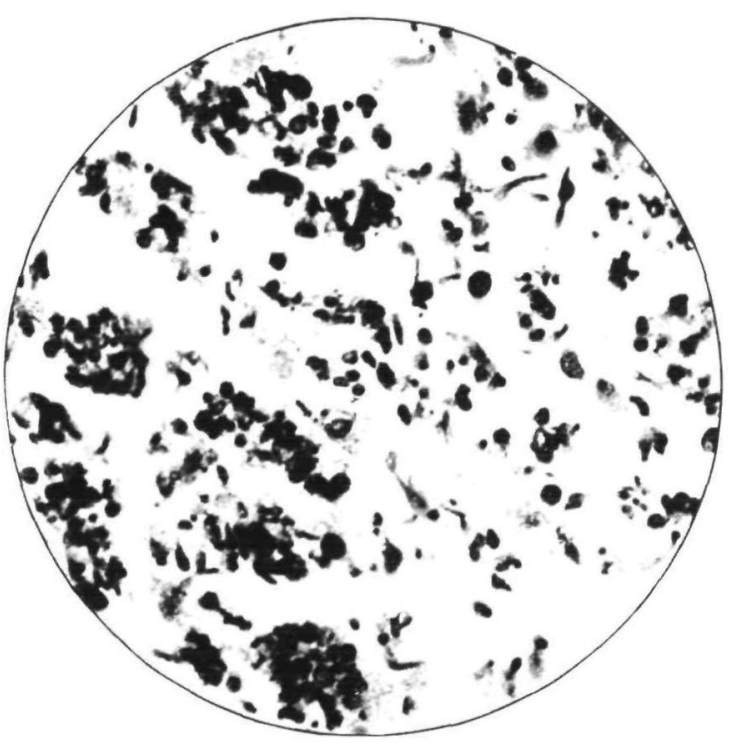

FiG. 3.

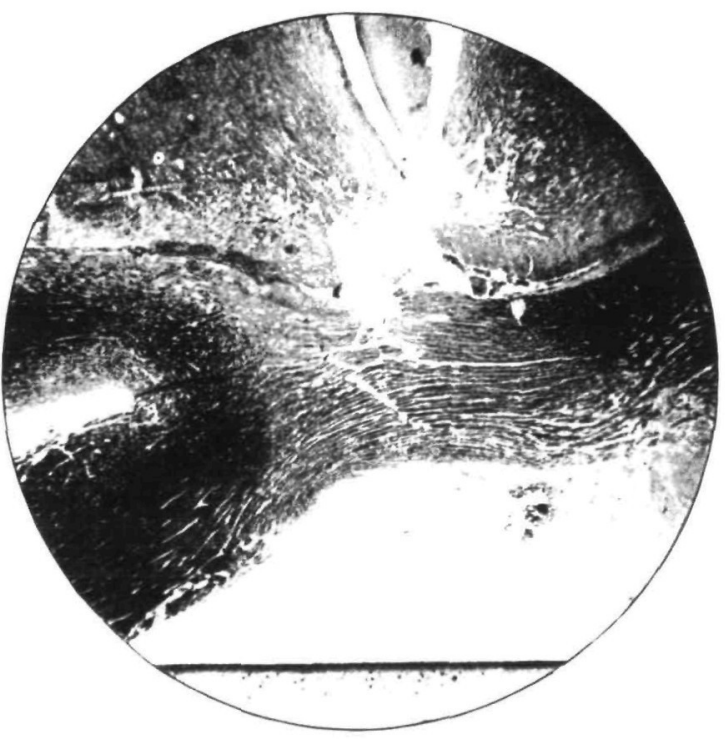

Fig. 4. 